\title{
Cardiolipin modulates allosterically peroxynitrite detoxification by horse heart cytochrome $c$
}

\author{
Paolo Ascenzi ${ }^{\mathrm{a}, *}$, Chiara Ciaccio ${ }^{\mathrm{b}, \mathrm{c}}$, Federica Sinibaldi ${ }^{\mathrm{b}}$, Roberto Santucci ${ }^{\mathrm{b}}$, Massimo Coletta ${ }^{\mathrm{b}, \mathrm{c}}$ \\ ${ }^{a}$ Department of Biology and Interdepartmental Laboratory for Electron Microscopy, University Roma Tre, I-00146 Roma, Italy \\ ${ }^{\mathrm{b}}$ Department of Experimental Medicine and Biochemical Sciences, University of Roma 'Tor Vergata', I-00133 Roma, Italy \\ ${ }^{\mathrm{c}}$ Interuniversity Consortium for the Research on the Chemistry of Metals in Biological Systems, I-70126 Bari, Italy
}

\section{A R T I C L E I N F O}

Article history:

Received 12 November 2010

Available online 24 November 2010

\section{Keywords:}

Horse heart cytochrome $c$

Cardiolipin

Peroxynitrite isomerization

Allostery

\begin{abstract}
A B S T R A C T
Upon interaction with bovine heart cardiolipin (CL), horse heart cytochrome $c$ (cytc) changes its tertiary structure disrupting the heme-Fe-Met80 distal bond, reduces drastically the midpoint potential out of the range required for its physiological role, binds $\mathrm{CO}$ and NO with high affinity, and displays peroxidase activity. Here, the effect of CL on peroxynitrite isomerization by ferric cytc (cytc-Fe(III)) is reported. In the absence of $\mathrm{CL}$, hexa-coordinated cytc does not catalyze peroxynitrite isomerization. In contrast, $\mathrm{CL}$ facilitates cytc-Fe(III)-mediated isomerization of peroxynitrite in a dose-dependent fashion inducing the penta-coordination of the heme-Fe(III)-atom. The value of the second order rate constant for CLcytc-Fe(III)-mediated isomerization of peroxynitrite $\left(k_{\text {on }}\right)$ is $(3.2 \pm 0.4) \times 10^{5} \mathrm{M}^{-1} \mathrm{~s}^{-1}$. The apparent dissociation equilibrium constant for CL binding to cytc-Fe(III) is $(5.1 \pm 0.8) \times 10^{-5} \mathrm{M}$. These results suggest that CL-cytc could play either pro-apoptotic or anti-apoptotic effects facilitating lipid peroxidation and scavenging of reactive nitrogen species, such as peroxynitrite, respectively.
\end{abstract}

(c) 2010 Elsevier Inc. All rights reserved.

\section{Introduction}

Cytochrome $c$ (cytc) is a peripheral membrane heme-protein functioning in-between the inner and the outer membrane of the mitochondrion mediating electron transfer between different proteins of the respiratory chain. Moreover, cytc plays a primary role in apoptosis [1-5]; indeed, in response to a variety of apoptosis inducing agents, cytc is released into the cytosol where it actively participates in the execution of programmed cell death by binding to the apoptosis protease activation factor (i.e., APAF-1) with the subsequent activation of pro-caspase-9 [6-9].

Approx $15 \%$ of mitochondrial cytc is tightly bound to the inner mitochondrial membrane being involved in the peroxidase activity, an event considered crucial for initiating the apoptotic process. In contrast, free cytc participates in the electron transfer process and inhibits reactive oxygen species formation (thus preventing cell oxidative stress). Among the phospholipids constituting the mitochondrial membrane, cardiolipin (CL) is considered the preferential interacting partner with cytc; this phospholipid (which represents about $20 \%$ of total lipids of the membrane) possesses a

Abbreviations: CL, cardiolipin; CL-cytc-Fe(III), cardiolipin-ferric cytochrome c complex; cytc-Fe(III), ferric cytochrome c; HSA-heme-Fe(III), ferric HSA-heme.

* Corresponding author. Fax: +39 0657336321.

E-mail address: ascenzi@uniroma3.it (P. Ascenzi). unique structure containing four (instead of two) fatty acid tails [10].

The CL-cytc interaction plays an important role in modulating the protein function and, consequently, the cell fate. At the early stage of apoptosis, the CL-cytc affinity decreases leading to the dissociation of the CL-cytc complex and the release of the free protein in the cytosol $[4,11]$. CL-bound cytc shows a non-native tertiary structure, a disrupted heme-Fe-Met80 distal bond [12-17], and a drastically reduced midpoint potential, which falls out of the range required for its physiological role [18]. Further, the cleavage of the distal Fe-Met80 bond endows cytc with a high affinity for $\mathrm{CO}$ and NO $[19,20]$ and peroxidase activity [21-27].

The peroxidase activity acquired by mitochondrial CL-bound cytc is critical during the early stages of the apoptotic process generating CL hydroperoxides. These compounds favor the dissociation of the CL-cytc complex and the release of free soluble cytc from the mitochondrial membrane in the cytosol $[11,23,28]$. Remarkably, the affinity of CO and NO for the CL-cytc complex is high enough to envisage an antiapoptotic effect of nanomolar $\mathrm{CO}$ and NO concentrations via inhibition of the cytc peroxidase activity $[19,20]$.

The high reactivity of the penta-coordinated CL-cytc complex $[11,19,20,26]$ prompted us to investigate the effect of CL on peroxynitrite isomerization by ferric cytc (cytc-Fe(III)). In the absence of $\mathrm{CL}$, hexa-coordinated cytc does not catalyze peroxynitrite isomerization, even though it has been shown that peroxynitrite may 
induce the very slow nitration (30 min) of the solvent-exposed Tyr74 residue; this leads to the cleavage of the Fe-Met80 bond, which is substituted by a weak Fe-Lys72 ligation [29]. In contrast, $\mathrm{CL}$ facilitates the fast cytc-Fe(III)-mediated isomerization of peroxynitrite in a dose-dependent fashion, inducing the penta-coordination of the heme-Fe(III)-atom. These results suggest that the CLcytc complex could display multiple pro- and anti-apoptotic roles interacting with reactive oxygen and nitrogen species.

\section{Materials and methods}

Ferric horse heart cytochrome $c$ (cytc-Fe(III)) and bovine heart CL were obtained from Sigma-Aldrich (St. Louis, MO, USA). All the other products were purchased from Merck AG (Darmstadt, Germany). The cytc-Fe(III) concentration was determined spectrophotometrically at $410 \mathrm{~nm}\left(\varepsilon_{410} \mathrm{~nm}=1.06 \times 10^{5} \mathrm{M}^{-1} \mathrm{~cm}^{-1}\right)$ [30]. Aqueous dispersions of CL liposomes were prepared as previously reported [17].

Peroxynitrite was synthesized from both $\mathrm{KO}_{2}$ and $\mathrm{NO}$ or $\mathrm{HNO}_{2}$ and $\mathrm{H}_{2} \mathrm{O}_{2}$ and stored at $-80.0^{\circ} \mathrm{C}$. The concentration of peroxynitrite was determined spectrophotometrically by measuring the absorbance at $302 \mathrm{~nm}\left(\varepsilon_{302} \mathrm{~nm}=1.705 \times 10^{3} \mathrm{M}^{-1} \mathrm{~cm}^{-1}\right)[31,32]$.

Kinetics of peroxynitrite isomerization by cytc-Fe(III), in the absence and presence of $\mathrm{CL}$ (final concentration, $2.0 \times 10^{-5} \mathrm{M} \leqslant$ $\left.[C L] \leqslant 1.6 \times 10^{-4} \mathrm{M}\right)$, was recorded at $302 \mathrm{~nm}\left(\varepsilon_{302 \mathrm{~nm}}=1.705 \times\right.$ $10^{3} \mathrm{M}^{-1} \mathrm{~cm}^{-1}$ ) by rapid mixing either the cytc-Fe(III) solution (final concentration, $1.0 \times 10^{-6} \mathrm{M} \leqslant[$ cytc-Fe(III) $] \leqslant 5.0 \times 10^{-6} \mathrm{M}$ ) or the CL-cytc-Fe(III) solution (final concentration, $2.0 \times 10^{-5} \mathrm{M} \leqslant$ $[\mathrm{CL}] \leqslant 1.6 \times 10^{-4} \mathrm{M}, \quad$ and $1.0 \times 10^{-6} \mathrm{M} \leqslant[\mathrm{cyt} c-\mathrm{Fe}(\mathrm{III})] \leqslant 5.0 \times$ $10^{-6} \mathrm{M}$ ) with the peroxynitrite solution (final concentration, [peroxynitrite] $=1.0 \times 10^{-4} \mathrm{M}$ ). The light path of the observation cuvette was $10 \mathrm{~mm}$, and the dead-time was $1.4 \mathrm{~ms}$. No gaseous phase was present [33].

Kinetics of peroxynitrite isomerization by cytc-Fe(III), in the absence and presence of $\mathrm{CL}$, was analyzed in the framework of the minimum reaction Scheme 1 [33].

Values of the pseudo-first-order rate constant for cytc-Fe(III)mediated peroxynitrite isomerization $\left(k_{\text {obs }}\right)$, in the absence and presence of $\mathrm{CL}$, have been determined from the analysis of the time-dependent absorbance decrease at $302 \mathrm{~nm}$, according to Eq. (1) [33]:

$$
[\text { peroxynitrite }]_{\mathrm{t}}=[\text { peroxynitrite }]_{\mathrm{i}} \times \mathrm{e}^{-k o b s \times t}
$$

Values of the second-order rate constant for CL-cytc-Fe(III)mediated peroxynitrite isomerization $\left(k_{\mathrm{on}}\right)$ and of the first-order rate constant for peroxynitrite isomerization in the absence of either cytc-Fe(III) or $\mathrm{CL}\left(k_{0}\right)$ have been determined from the linear dependence of $k_{\text {obs }}$ on the (CL-)cytc-Fe(III) concentration, according to Eq. (2) [33]:

$k_{\mathrm{obs}}=k_{\mathrm{on}} \times[\mathrm{cytc}-\mathrm{Fe}(\mathrm{III})]+k_{0}$

The value of the apparent dissociation equilibrium constant for $\mathrm{CL}$ binding to cytc-Fe(III) $(K)$ has been determined from the dependence of $k_{\mathrm{on}}$ on the CL concentration (i.e., [CL]), according to Eq. (3):

$k_{\text {on }}=k_{\text {on }(\text { top })} \times[\mathrm{CL}] /(K+[\mathrm{CL}])$

where $k_{\text {on(top) }}$ is the asymptotic value of $k_{\text {on }}$ under conditions where $[\mathrm{CL}] \gg \mathrm{K}$.
All data were obtained at $\mathrm{pH} 7.0\left(3.0 \times 10^{-2} \mathrm{M}\right.$ Hepes buffer $)$ and $20.0^{\circ} \mathrm{C}$. The effect of $1.0 \mathrm{M} \mathrm{KCl}$ on values of $k_{\text {on }}$ and $k_{0}$ has been also investigated.

$\mathrm{NO}_{2}^{-}$and $\mathrm{NO}_{3}^{-}$analysis was carried out spectrophotometrically at $543 \mathrm{~nm}$ by using the Griess reagent and $\mathrm{VCl}_{3}$ to catalyze the conversion of $\mathrm{NO}_{3}^{-}$to $\mathrm{NO}_{2}^{-}$, as described previously [33]

Kinetic and thermodynamic data were analyzed using the MatLab program (The Math Works Inc., Natick, MA, USA). The results are given as mean values of at least four experiments plus or minus the corresponding standard deviation.

\section{Results and discussion}

Kinetics of peroxynitrite isomerization by (CL-)cytc-Fe(III) was fitted to a single-exponential decay for more than $90 \%$ of its course (Fig. 1, panel A). This indicates that no intermediate species (e.g., (CL-)cytc-Fe(III)-OONO; see Scheme 1) accumulate(s) in the course of peroxynitrite isomerization, the formation of the transient (CL-)cytc-Fe(III)-OONO species representing the rate limiting step in catalysis.

In the absence of $\mathrm{CL}$, values of $k_{\text {obs }}$ for peroxynitrite isomerization are unaffected by cytc-Fe(III) over the whole concentration range explored $\left(1.0 \times 10^{-6}-5.0 \times 10^{-6} \mathrm{M}\right)$. Indeed, values of $k_{\mathrm{obs}}$ are independent of the cytc-Fe(III) concentration and correspond to $k_{0}$ (i.e., the first-order rate constant for the spontaneous isomerization of peroxynitrite) within the experimental error (Fig. 1, panel B). This indicates that cytc-Fe(III) does not catalyzes peroxynitrite isomerization. In contrast, values of $k_{\text {obs }}$ for CLcytc-Fe(III)-mediated isomerization of peroxynitrite increase with the CL-cytc-Fe(III) concentration (Fig. 1, panel C), indicating that the $\mathrm{CL}$-cytc-Fe(III) complex catalyzes peroxynitrite isomerization. The analysis of data according to Eq. (2) allowed the determination of values of $k_{\text {on }}$ (corresponding to the slope of the linear plots) and $k_{0}$ (corresponding to the $y$ intercept of the linear plots) for CL-cytc-Fe(III)-catalyzed isomerization of peroxynitrite at $2.0 \times$ $10^{-5} \mathrm{M} \leqslant[\mathrm{CL}] \leqslant 1.6 \times 10^{-4} \mathrm{M}$. Under all the experimental conditions, values of $k_{0}$ are in good agreement with those reported in the literature [33-38]. According to literature [24], high ionic strength (i.e., $1.0 \mathrm{M} \mathrm{KCl}$ ) inhibits the $\mathrm{CL}$-cytc-Fe(III)-catalyzed isomerization of peroxynitrite impairing the formation of the CLcytc-Fe(III) complex (Fig. 1, panel B).

As shown in Fig. 1 (panel D), CL facilitates cytc-Fe(III)-mediated isomerization of peroxynitrite in a dose-dependent fashion. Indeed, values of $k_{\text {on }}$ increase on increasing the CL concentration. The analysis of data according to Eq. (3) allowed the determination of both values of $K \quad\left(=(5.1 \pm 0.8) \times 10^{-5} \mathrm{M}\right)$ and $k_{\text {on(top })}$ $\left(=(3.2 \pm 0.4) \times 10^{5} \mathrm{M}^{-1} \mathrm{~s}^{-1}\right)$.

As shown in Table $1, \mathrm{CL}$-cytc-Fe(III) catalyzes peroxynitrite isomerization, $\mathrm{NO}_{3}^{-}$and $\mathrm{NO}_{2}^{-}$yields being $91 \%$ and $8 \%$, respectively. In contrast, the $\mathrm{NO}_{3}^{-}$and $\mathrm{NO}_{2}^{-}$yield decreases (75\%) and increases (26\%), respectively, in the presence of cytc-Fe(III) or $\mathrm{CL}$ or $\mathrm{KCl}$. As expected [24], peroxynitrite isomerization yields $72 \% \mathrm{NO}_{3}^{-}$and $26 \% \mathrm{NO}_{2}^{-}$in the presence of CL-cytc-Fe(III) and $1.0 \mathrm{M} \mathrm{KCl}$.

Catalytic isomerization of peroxynitrite appears to be a common feature of penta-coordinated ferric heme-proteins, i.e., CLcytc-Fe(III) (present study), HSA-heme-Fe(III) [33], horse Mb [34], sperm whale $\mathrm{Mb}(\mathrm{III})$ [35], and human $\mathrm{Hb}(\mathrm{III})$ [34]. Notably, hexacoordinated human neuroglobin does not catalyze peroxynitrite isomerization [39]. 

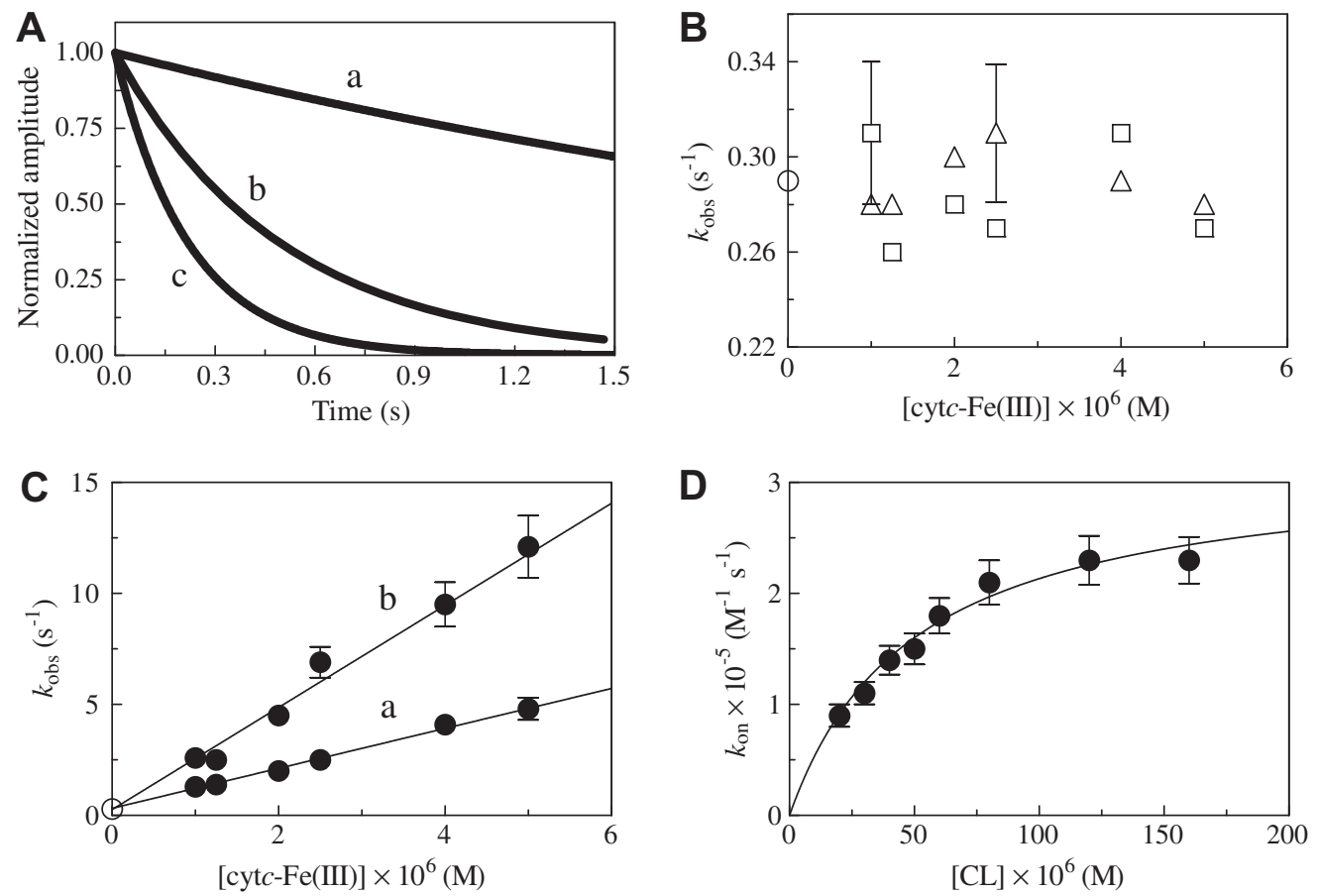

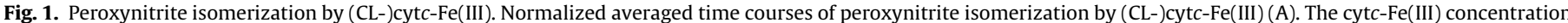

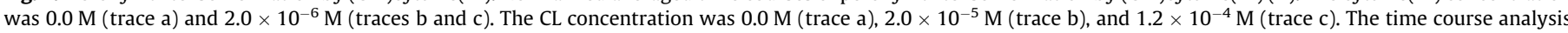

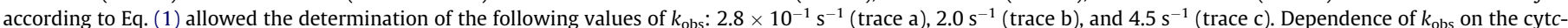

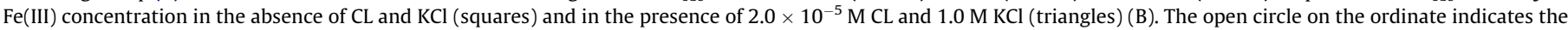

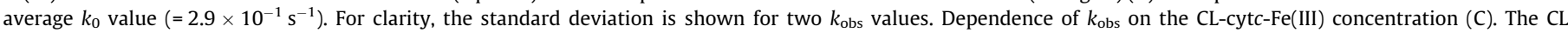

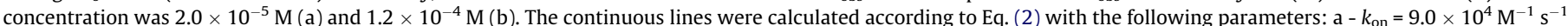

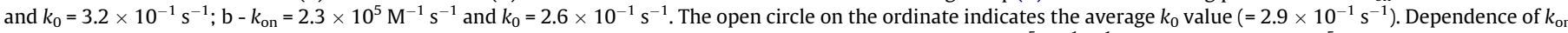

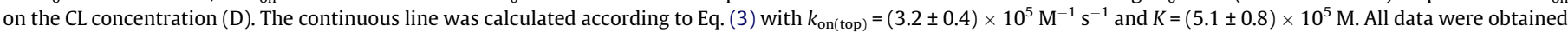
at $\mathrm{pH} 7.0$ and $20.0^{\circ} \mathrm{C}$. Where not shown, standard deviation is smaller than the symbol. For details, see text.

Table 1

$\mathrm{NO}_{3}^{-}$and $\mathrm{NO}_{2}^{-}$distribution of peroxynitrite isomerization in the absence and presence of cytc-Fe(III), $\mathrm{CL}$, and $\mathrm{KCl}$, at $\mathrm{pH} 7.0$ and $20.0^{\circ} \mathrm{C}$. ${ }^{\mathrm{a}}$

\begin{tabular}{lllllr}
\hline $\begin{array}{l}\text { cytc-Fe(III) } \\
(\mathrm{M})\end{array}$ & {$[\mathrm{CL}](\mathrm{M})$} & $\begin{array}{l}\mathrm{KCl} \\
(\mathrm{M})\end{array}$ & $\begin{array}{l}{\left[\mathrm{NO}_{3}^{-}\right]} \\
(\%)\end{array}$ & \multicolumn{1}{l}{$\begin{array}{l}{\left[\mathrm{NO}_{2}^{-}\right]} \\
(\%)\end{array}$} & \multicolumn{1}{c}{$\left[\begin{array}{c}{\left[\mathrm{NO}_{3}^{-}\right]+\left[\mathrm{NO}_{2}^{-}\right]} \\
(\%)\end{array}\right.$} \\
\hline- & - & - & $76 \pm 6$ & $25 \pm 4$ & 101 \\
$4.0 \times 10^{-5}$ & - & - & $73 \pm 6$ & $26 \pm 4$ & 99 \\
- & $3.0 \times 10^{-4}$ & - & $74 \pm 7$ & $27 \pm 3$ & 101 \\
- & - & 1.0 & $75 \pm 7$ & $25 \pm 3$ & 100 \\
$4.0 \times 10^{-5}$ & $3.0 \times 10^{-4}$ & - & $91 \pm 8$ & $8 \pm 3$ & 99 \\
$4.0 \times 10^{-5}$ & $3.0 \times 10^{-4}$ & 1.0 & $72 \pm 8$ & $26 \pm 3$ & 98 \\
\hline
\end{tabular}

a The peroxynitrite concentration is $1.0 \times 10^{-4} \mathrm{M}$.

Table 2

Values of $k_{\text {on }}$ for peroxynitrite scavenging by ferric heme-proteins.

\begin{tabular}{lllll}
\hline & $k_{\text {on }}\left(\mathrm{M}^{-1} \mathrm{~s}^{-1}\right)$ & $\mathrm{pH}$ & $T\left({ }^{\circ} \mathrm{C}\right)$ & Ref. \\
\hline CL-cytc $^{\mathrm{a}}$ & $3.2 \times 10^{5}$ & 7.0 & 20.0 & Present study \\
HSA-heme-Fe & $4.1 \times 10^{5}$ & 7.2 & 22.0 & {$[33]$} \\
Horse heart Mb & $2.9 \times 10^{4}$ & 7.0 & 20.0 & {$[34]$} \\
Sperm whale Mb & $1.6 \times 10^{4}$ & 7.5 & 20.0 & {$[39]$} \\
Human Hb & $1.2 \times 10^{4}$ & 7.5 & 20.0 & {$[34]$} \\
\hline
\end{tabular}

${ }^{\text {a }}[\mathrm{CL}]>$ $K$; see text.

Note that the $k_{\mathrm{on}}$ value for peroxynitrite isomerization by CLcytc-Fe(III) is similar to that for HSA-heme-Fe(III) action $[33,37,38]$ and is higher by about one order of magnitude than those reported for horse $\mathrm{Mb}(\mathrm{III})$ [34], sperm whale $\mathrm{Mb}(\mathrm{III})$ [35], and human $\mathrm{Hb}(\mathrm{III})$ [34] (Table 2).

Peroxynitrite isomerization by cytc-Fe(III) (present study) and HSA-heme-Fe(III) [33] is modulated allosterically by CL and drugs,

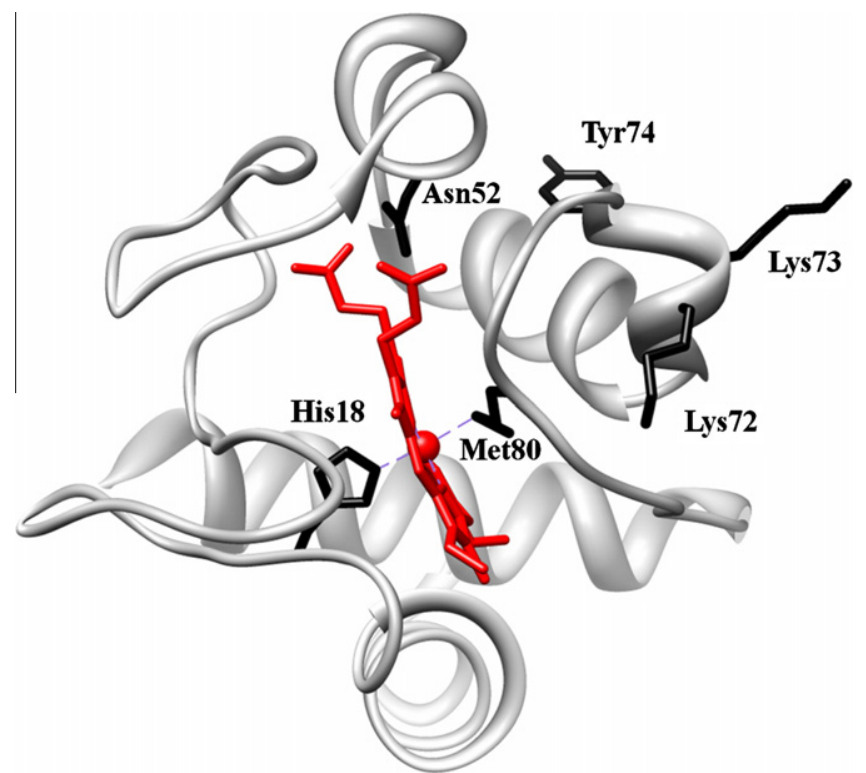

Fig. 2. Ribbon structure of horse heart cyt $c$. The heme is shown in red. Residues His18 and Met80 coordinate the heme-Fe-atom (bonds are represented as dashed lines). Residues Asn52, Lys72, and Lys73 could play a critical role in the interaction with CL. The Lys72 residue replaces Met80 as the sixth coordination ligand of the heme-Fe-atom upon the very slow peroxynitrite-induced nitration of the solventexposed Tyr74 residue. The molecular graphics image (PDB: 1HRC) was produced using the UCSF Chimera package [40]. (For interpretation of the references to colour in this figure legend, the reader is referred to the web version of this article.)

respectively. In particular, $\mathrm{CL}$ acts as an allosteric activator of cytc$\mathrm{Fe}(\mathrm{III})$ by binding to specific regions of the protein (see Fig. 2); 
upon the CL-cytc complex formation, the heme pocket region is altered and penta-coordination of the heme-Fe(III)-atom is facilitated. In contrast, HSA-heme-Fe(III)-mediated peroxynitrite isomerization is allosterically inhibited by drug binding to both Sudlow's site I and II (e.g., warfarin and ibuprofen, respectively). Indeed, drug binding to HSA-heme-Fe(III) induces the distortion of the heme geometry and the hexa-coordination of the heme$\mathrm{Fe}(\mathrm{III})$-atom, impairing HSA-heme-Fe(III) reactivity (e.g., peroxynitrite isomerization) $[33,37,38]$.

In conclusion, it appears evident that CL binding to cytc induces tertiary changes facilitating the cleavage of the distal hemeFe-Met80 bond, and favoring the enzymatic activity of CL-bound cytc. This structural change(s) seems different from that observed upon the very slow peroxynitrite-induced nitration $(30 \mathrm{~min}$ ) of Tyr74 in hexa-coordinated cytc [29]. Therefore, data obtained so far suggest that the CL-cytc complex could act as either a pro- or an anti-apoptotic factor, depending on the conditions under which it operates. In particular, the CL-cytc complex functions as a proapoptotic factor catalyzing the peroxidative reduction of $\mathrm{H}_{2} \mathrm{O}_{2}$ which leads to $\mathrm{CL}$ peroxidation. In contrast, the CL-cytc complex exerts an anti-apoptotic action facilitating the isomerization of peroxynitrite to nitrate with the consequent scavenging of reactive nitrogen species. Further, the reaction of NO with the ferrous CL-cytc complex impairs the cytc enzymatic activity, thus exerting a protecting effect from programmed cell death [20].

As a whole, these examples envisage the potentialities of CL-bound cytc to act as a modulator of the apoptotic process, according to the levels and the type of oxidizing species present in the cellular microenvironment. The capability of triggering either pro- and/or anti-apoptotic processes renders the CL-cytc complex a crucial element for the regulation of the cell life program, thus opening a new (although complex) scenario where the role of cytc appears to be significantly more extensive than what thought so far.

\section{Acknowledgments}

Authors wish to thank Prof. Luigi Casella (University of Pavia, Italy), Prof. Giulietta Smulevich (University of Firenze, Italy), and Prof. Mauro Fasano (University of Insubria, Busto Arsizio (VA), Italy) for helpful discussions. This work was partially supported by grants from the Ministero dell'Istruzione, dell'Università e della Ricerca of Italy (University Roma Tre, CLAR 2010, to P.A.).

\section{References}

[1] H. Bayir, B. Fadeel, M.J. Palladino, E. Witasp, I.V. Kurnikov, Y.Y. Tyurina, V.A Tyurin, A.A. Amoscato, J. Jiang, P.M. Kochanek, S.T. DeKosky, J.S. Greenberger, A.A. Shvedova, V.E. Kagan, Apoptotic interactions of cytochrome c: redox flirting with anionic phospholipids within and outside of mitochondria, Biochim. Biophys. Acta 1757 (2006) 648-659.

[2] S. Orrenius, V. Gogvadze, B. Zhivotovsky, Mitochondrial oxidative stress: implications for cell death, Annu. Rev. Pharmacol. Toxicol. 47 (2007) 143-183.

[3] Y.-L.P. Ow, D.R. Green, Z. Hao, T.W. Mak, Cytochrome c: functions beyond respiration, Nat. Rev. Mol. Cell Biol. 9 (2008) 532-542.

[4] P. Caroppi, F. Sinibaldi, L. Fiorucci, R. Santucci, Apoptosis and human diseases: mitochondrion damage and lethal role of cytochrome $c$ as proapoptotic protein, Curr. Med. Chem. 16 (2009) 4058-4065.

[5] P.B. Pun, J. Lu, E.M. Kan, S. Moochhala, Gases in the mitochondria Mitochondrion 10 (2010) 83-93

[6] H. Zou, Y. Li, X. Liu, X. Wang, An APAF-1 cytochrome $c$ multimeric complex is a functional apoptosome that activates procaspase-9, J. Biol. Chem. 274 (1999) 11549-11556

[7] C. Purring-Koch, G. McLendon, Cytochrome $c$ binding to Apaf-1: the effects of dATP and ionic strength, Proc. Natl Acad. Sci. USA 97 (2000) 11928-11931.

[8] D. Twiddy, D.G. Brown, C. Adrain, R. Jukes, S.J. Martin, G.M. Cohen, M. MacFarlane, K. Cain, Pro-apoptotic proteins released from the mitochondria regulate the protein composition and caspase-processing activity of the native Apaf-1/caspase-9 apoptosome complex, J. Biol. Chem. 279 (2004) 1966519682.
[9] C. Garrido, L. Galluzzi, M. Brunet, P.E. Puig, C. Didelot, G. Kroemer, Mechanisms of cytochrome $c$ release from mitochondria, Cell Death Differ. 13 (2006) 14231433.

[10] R.N. Lewis, R.N. McElhaney, The physicochemical properties of cardiolipin bilayers and cardiolipin-containing lipid membranes, Biochim. Biophys. Acta 1788 (2009) 2069-2079.

[11] V.E. Kagan, H.A. Bayir, N.A. Belikova, Y.Y. Tyurina, V.A. Tyurin, J. Jiang, D.A. Stoyanovsky, P. Wipf, P.M. Kochanek, J.S. Greenberger, B. Pitt, A.A. Shvedova, G. Borisenko, Cytochrome $c$ cardiolipin relations in mitochondria, Free Radic. Biol. Med. 46 (2009) 1439-1453.

[12] M. Rytömaa, P.K.J. Kinnunen, Evidence for two distinct acidic phospholipidsbinding sites in cytochrome $c$, J. Biol. Chem. 269 (1994) 1770-1774.

[13] M. Rytömaa, P.K.J. Kinnunen, Reversibility of the binding of cytochrome c liposomes: implications for lipid-protein interactions, J. Biol. Chem. 270 (1995) 3197-3202.

[14] E.K. Tuominen, C.J. Wallace, P.K.J. Kinnunen, Phospholipid-cytochrome $c$ interaction: evidence for the extended lipid anchorage, J. Biol. Chem. 277 (2002) 8822-8826.

[15] E. Kalanxhi, C.J.A. Wallace, Cytochrome $c$ impaled: investigation of the extended lipid anchorage of a soluble protein to mitochondrial membrane models, Biochem. J. 407 (2007) 179-187.

[16] F. Sinibaldi, L. Fiorucci, A. Patriarca, R. Lauceri, T. Ferri, M. Coletta, R. Santucci, Insights into cytochrome $c$-cardiolipin interaction: role played by ionic strength, Biochemistry 47 (2008) 6928-6935.

[17] F. Sinibaldi, B.D. Howes, M.C. Piro, F. Polticelli, C. Bombelli, T. Ferri, M. Coletta, G. Smulevich, R. Santucci, Extended cardiolipin anchorage to cytochrome $c$ : a model for protein-mitochondrial membrane binding, J. Biol. Inorg. Chem. 15 (2010) 689-700.

[18] L.V. Basova, I.V. Kurnikov, L. Wang, V.B. Ritov, N.A. Belikova, I.I. Vlasova, A.A Pacheco, D.E. Winnica, J. Peterson, H. Bayir, D.H. Waldeck, V.E. Kagan, Cardiolipin switch in mitochondria: shutting off the reduction of cytochrome $c$ and turning on the peroxidase activity, Biochemistry 46 (2007) 3423-3434.

[19] S.M. Kapetanaki, G. Silkstone, I. Husu, U. Liebl, M.T. Wilson, M.H. Vos, Interaction of carbon monoxide with the apoptosis-inducing cytochrome $c$ cardiolipin complex, Biochemistry 48 (2009) 1613-1619.

[20] G. Silkstone, S.M. Kapetanaki, I. Husu, M.H. Vos, M.T. Wilson, Nitric oxide binds to the proximal heme coordination site of the ferrocytochrome $c /$ cardiolipin complex: formation mechanism and dynamics, J. Biol. Chem. 285 (2010) 19785-19792.

[21] Y.R. Chen, L.J. Deterding, B.E. Sturgeon, K.B. Tomer, R.P. Mason, Protein oxidation of cytochrome $c$ by reactive halogen species enhances its peroxidase activity, J. Biol. Chem. 277 (2002) 29781-29791.

[22] R.E. Diederix, M. Ubbink, G.W. Canters, Peroxidase activity as a tool for studying the folding of c-type cytochromes, Biochemistry 41 (2002) 1306713077.

[23] V.E. Kagan, V.A. Tyurin, J. Jiang, Y.Y. Tyurina, V.B. Ritov, A.A. Amoscato, A.N. Osipov, N.A. Belikova, A.A. Kapralov, V. Kini, I.I. Vlasova, Q. Zhao, M. Zou, P. Di, D.A. Svistunenko, I.V. Kurnikov, G.G. Borisenko, Cytochrome $c$ acts as a cardiolipin oxygenase required for release of proapoptotic factors, Nat. Chem. Biol. 1 (2005) 223-232.

[24] N.A. Belikova, Y.A Vladimirov, A.N. Osipov, A.A. Kapralov, V.A. Tyurin, M.V. Potapovich, L.V. Basova, J. Peterson, I.V. Kurnikov, V.E. Kagan, Peroxidase activity and structural transitions of cytochrome $c$ bound to cardiolipincontaining membranes, Biochemistry 45 (2006) 4998-5009.

[25] A.A. Kapralov, I.V. Kurnikov, I.I. Vlasova, N.A. Belikova, V.A. Tyurin, L.V. Basova, Q. Zhao, Y.Y. Tyurina, J. Jiang, H. Bayir, Y.A. Vladimirov, V.E. Kagan, The hierarchy of structural transitions induced in cytochrome $c$ by anionic phospholipids determines its peroxidase activation and selective peroxidation during apoptosis in cells, Biochemistry 46 (2007) 14232-14244.

[26] N.A. Belikova, Y.Y. Tyurina, G. Borisenko, V. Tyurin, A.K. Samhan Arias, N. Yanamala, P.G. Furtmüller, J. Klein-Seetharaman, C. Obinger, V.E. Kagan, Heterolytic reduction of fatty acid hydroperoxides by cytochrome c/cardiolipin complexes: antioxidant function in mitochondria, J. Am. Chem. Soc. 131 (2009) 11288-11289.

[27] A. Patriarca, T. Eliseo, F. Sinibaldi, M.C. Piro, R. Melis, M. Paci, D.O. Cicero, F. Polticelli, R. Santucci, L. Fiorucci, ATP acts as a regulatory effector in modulating structural transitions of cytochrome $c$ : implications for apoptotic activity, Biochemistry 48 (2009) 3279-3287.

[28] R. Santucci, F. Sinibaldi, A. Patriarca, D. Santucci, L. Fiorucci, Misfolded proteins and neurodegenerative diseases: mitochondrial dysfunction and role of nonnative states of cytochrome $c$ in cell apoptosis, Exp. Rev. Proteomics 7 (2010) 507-517.

[29] L.A. Abriata, A. Cassina, V. Tortora, M. Marin, J.M. Souza, L. Castro, A.J. Vila, R. Radi, Nitration of solvent-exposed Tyrosine 74 on cytochrome $c$ triggers heme iron-Methionine 80 bond disruption: nuclear magnetic resonance and optical spectroscopy studies, J. Biol. Chem. 284 (2009) 17-26.

[30] E. Margoliash, N. Frohwirt, Spectrum of horse-heart cytochrome $c$, Biochem. J. 71 (1959) 570-572.

[31] D.S. Bohle, P.A. Glassbrenner, B. Hansert, Syntheses of pure tetramethylammonium peroxynitrite, Methods Enzymol. 269 (1996) 302-311.

[32] W.H. Koppenol, R. Kissner, J.S. Beckman, Syntheses of peroxynitrite: to go with the flow or on solid grounds?, Methods Enzymol 269 (1996) 296-302.

[33] P. Ascenzi, A. di Masi, M. Coletta, C. Ciaccio, G. Fanali, F.P. Nicoletti, G. Smulevich, M. Fasano, Ibuprofen impairs allosterically peroxynitrite isomerization by ferric human serum heme-albumin, J. Biol. Chem. 284 (2009) 31006-31017. 
[34] S. Herold, S. Kalinga, Metmyoglobin and methemoglobin catalyze the isomerization of peroxynitrite to nitrate, Biochemistry 42 (2003) 1403614046.

[35] S. Herold, S. Kalinga, T. Matsui, Y. Watanabe, Mechanistic studies of the isomerization of peroxynitrite to nitrate catalyzed by distal histidine metmyoglobin mutants, J. Am. Chem. Soc. 126 (2004) 6945-6955.

[36] S. Goldstein, J. Lind, G. Merényi, Chemistry of peroxynitrites and peroxynitrates, Chem. Rev. 105 (2005) 2457-2470.

[37] P. Ascenzi, A. Bolli, A. di Masi, G.R. Tundo, G. Fanali, M. Coletta, M. Fasano, Isoniazid and rifampicin inhibit allosterically heme binding to albumin and peroxynitrite isomerization by heme-albumin, J. Biol. Inorg. Chem. (2010), doi:10.1007/s00775-010-0706-2.
[38] P. Ascenzi, A. Bolli, F. Gullotta, G. Fanali, M. Fasano, Drug binding to Sudlow's site I impairs allosterically human serum heme-albumin-catalyzed peroxynitrite detoxification, IUBMB Life 62 (2010) 776-780.

[39] S. Herold, A. Fago, R.E. Weber, S. Dewilde, L. Moens, Reactivity studies of the $\mathrm{Fe}(\mathrm{III})$ and $\mathrm{Fe}(\mathrm{II}) \mathrm{NO}$ forms of human neuroglobin reveal a potential role against oxidative stress, J. Biol. Chem. 279 (2004) 22841-22847.

[40] E.F. Pettersen, T.D. Goddard, C.C. Huang, G.S. Couch, D.M. Greenblatt, E.C. Meng, T.E. Ferrin, UCSF Chimera - A visualization system for exploratory research and analysis, J. Comput. Chem. 25 (2004) 1605-1612. 